\title{
Cycling pp'DDT and pp'DDE at a watershed scale: the case of Lago Maggiore (Italy)
}

\author{
Silvana GALASSI, Pietro VOLTA ${ }^{1) *}$, Alcide CALDERONI ${ }^{1)}$ and Licia GUZZELLA ${ }^{2)}$ \\ Dept. of Biology, University of Milan, Via Celoria 26, 20133 Milan, Italy \\ ${ }^{1)}$ CNR Institute of Ecosystem Study, Largo V. Tonolli 50, 28922, Verbania Pallanza, Italy \\ ${ }^{2)} \mathrm{CNR}$ Institute of Water Research, Via della Mornera 25, 20047 Brugherio (Milano), Italy \\ *e-mail corresponding author: p.volta@ise.cnr.it
}

\begin{abstract}
A point source of DDT pollution of industrial origin, discovered in 1996 in Lago Maggiore, the second largest $\left(212 \mathrm{~km}^{2}\right)$ and deepest $(373 \mathrm{~m})$ lake in Italy, created concern for wildlife and human health because contamination in some fish species exceeded the threshold for human consumption, even though the concentrations measured in the water were much lower than the legal requirements for drinking purposes. Some precautionary measures were undertaken to prevent DDT runoff from the industrial site to the lake but soil restoration had not yet been carried out. The first study to quantify land based sources of DDT homologue pollution was performed in 1998 by sampling all the main tributaries monthly in order to evaluate the annual load to the lake. From May 2001 to May 2002, the study was repeated in order to evaluate the degree of recovery. In this work we compared the results of that survey with those of a more recent campaign carried out from May 2001 to May 2002, concluding that land based sources are still relevant for pp'DDE, the most stable metabolite of pp'DDT, while they are negligible for the parent compound. Furthermore, the Toce River, receiving the soil runoff of the industrial area, was found to give the greatest contribution of DDT and DDE load to the lake in the past campaign, while its load drastically decreased in 2001-2002 in the case of pp'DDT, being comparable to that of Ticino River(the second biggest river of the Lago Maggiore basin, which rises in the St. Gotthard Massif of the Swiss Alpes). Air transport and cold condensation are very likely responsible for trapping DDT and DDE in high mountain glaciers, which represent a secondary pollution source.
\end{abstract}

Key words: DDT load, DDE load, OC cycling, organochlorine pollution

\section{INTRODUCTION}

A factory producing technical DDT discharged liquid wastes from 1948 to 1996 into the Toce River, a major inlet of Lago Maggiore, the second largest of the Italian subalpine lakes. In spite of the large lake volume $\left(37.5 \mathrm{~km}^{3}\right)$, the whole ecosystem was adversely affected by DDT homologue contamination. Benthic fauna, pelagic fish and top predators were the main targets of this pollution (Bettinetti et al. 2005).

Moreover, in order to prevent risk to human health from fish consumption, professional fishing of common commercial species was forbidden because the maximum admissible concentrations were exceeded (0.05 mg kg-1 of b.w., O.M. 18/07/1990). Although some remediation measures have been applied to the industrial area of Pieve Vergonte (VB) (Fig. 1), where DDT production was located, ten years after the cessation of DDT manufacturing some fish species still show contamination levels that are generally regarded as dangerous for top predators and human consumption. There is therefore an urgent need to know if natural restoration processes will lead to acceptable ecosystem conditions in the near future, or if a new restoration program must be implemented in the industrial area to speed up the recovery of the environment.
Unfortunately, the lake is particularly conservative with respect to DDT pollution: its theoretical residence time is 4 years but the real water renewal rate is longer in some parts of the lake. Pollutant removal by algal adsorption and sedimentation is not favoured because of the low production rate of lake and the consequent low concentration of particulate matter (Dachs et al. 2000). Finally, pollutant dilution in the atmospheric compartment is prevented on the Northern side by the Alps which represent a barrier to the exchange of air masses: high mountains trap POPs in winter snow and release them in the summer thaw (Villa et al. 2003).

Although many studies have been carried out to monitor organochlorine compound pollution in industrially contaminated water basins (EPA 1999), and predictive models calculating DDT distribution on a local scale (MacLeod \& Mackay 2004) are available, a lot of analytical and hydrological data are needed to feed these models, which are not available in the case of Lago Maggiore. Furthermore, uncertainty still exists as to the pp'DDT transformation rates in soil and water, which could be strongly influenced by local climatic and environmental conditions.

Therefore, a sampling campaign was carried out from May 2001 to May 2002 on the main Lago Maggiore tributaries to compare the total pp'DDT and 


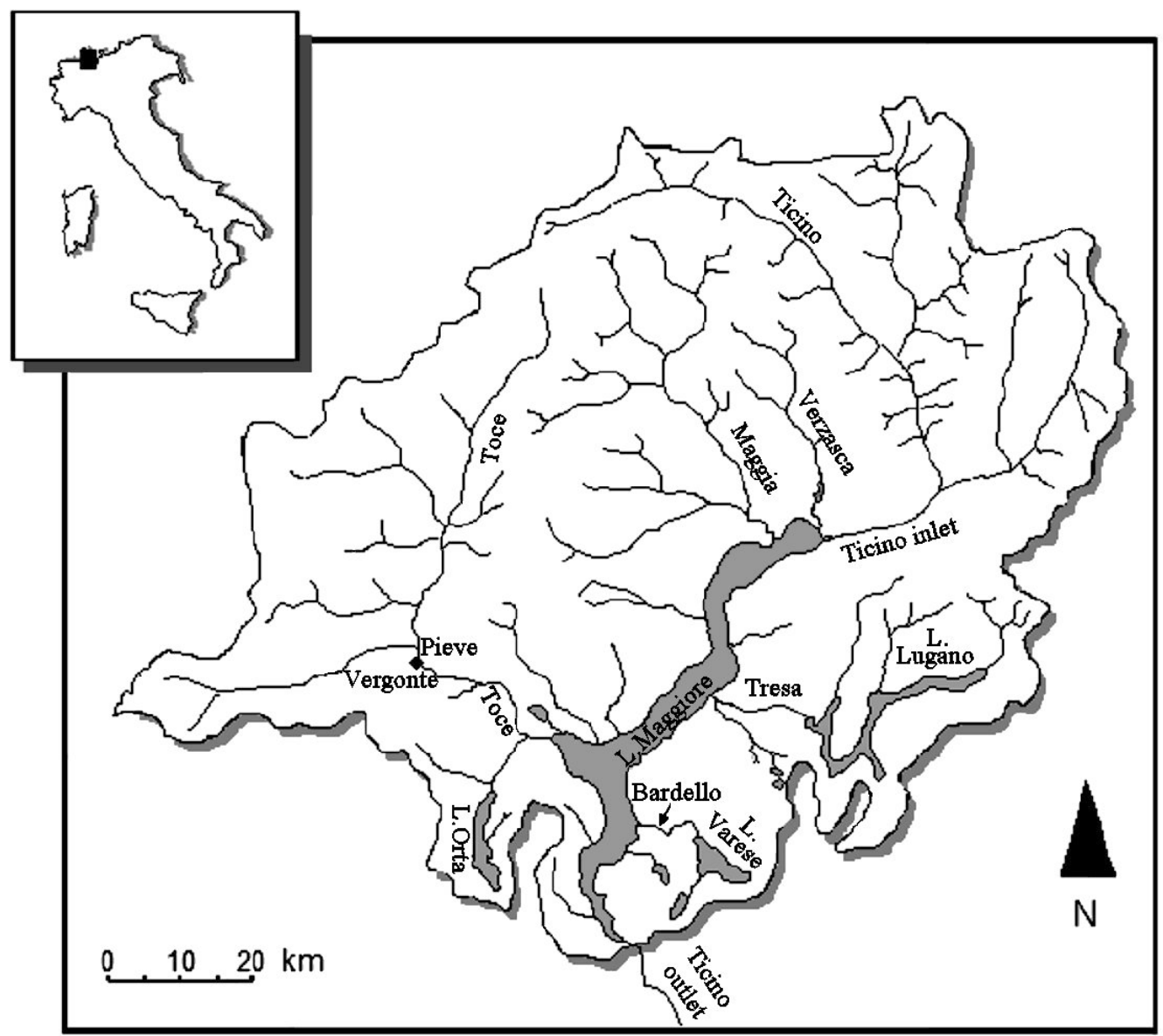

Fig. 1. Lago Maggiore, its basin, rivers and the location of DDT plant in Pieve Vergonte (black spot).

pp'DDE loads to that calculated in 1998 (Calderoni \& de Bernardi 1999), two years after the closure of the DDT plant. In this way, very useful information could be collected to evaluate both the residence time of these two pollutants at a watershed scale and the role of the local cycling in pollutant redistribution.

\section{METHODS}

\subsection{Sampling area}

Lago Maggiore has the largest watershed of the Italian lakes $\left(6599 \mathrm{~km}^{2}\right)$ and a lake surface of $212 \mathrm{~km}^{2}$ (Carollo et al. 1985). The northern part is defined by the Alps, with the highest peak (Monte Rosa, $4633 \mathrm{~m}$ a.s.1.). The main tributaries are Ticino River, Toce River, Tresa River and Maggia River (Fig. 1). These four rivers receive $77 \%$ of the basin drainage. The maximum discharge is from May to November, mainly due to snow melting and rainfall. The biggest flood event in the last hundred years occurred in October 2000: Toce River and Ticino River discharges were five fold higher and three fold higher respectively than the mean of the same period in the previous 20 years. The highest discharge for Toce River was $4200 \mathrm{~m}^{3} \mathrm{~s}^{-1}$, five fold bigger than in Ticino Inlet.

\subsection{Sampling and analytical determination of $D D T$ homologues in lake water}

The Toce, Maggia, Verzasca, Ticino, Tresa (after its confluence with the Margorabbia) and Bardello rivers were sampled monthly from May 2001 to May 2002 at their outlets. The River Ticino (outlet) was also sampled at the outlet of the lake (Fig. 1). Some rivers (Ticino, Verzasca, Maggia) could not be sampled in May 2002 because of a flood event.

The samples were transported to the lab at $4{ }^{\circ} \mathrm{C}$ in dark glass bottles and filtered within 24 hours. After filtration on $0.45 \mu \mathrm{m}$ cellulose acetate filters, 2 litres of water sample were added with $100 \mathrm{ml}$ of $\mathrm{n}$-hexane (Merck, pesticide analysis grade) and stored at $4{ }^{\circ} \mathrm{C}$ until extraction, carried out by magnetic stirring for one hour directly in the bottle used to store the sample, to minimize the loss of DDT homologues due to volatilization or adsorption onto the glass walls. Extraction was repeated with 75 and $25 \mathrm{ml}$ of $\mathrm{n}$-hexane, stirring the two phases for $15 \mathrm{~min}$.

Filters were covered by n-hexane, extracted by sonication and washed with small amounts of solvents.

Hexane extracts were combined, reduced to a small volume under vacuum and cleaned up on a Florisil ${ }^{\circledR}$ 
column (40 $\mathrm{mm} \times 0.7 \mathrm{~mm}$ I.D.) eluting with $25 \mathrm{ml}$ of n-hexane.

Purified water extracts were concentrated to exactly $0.5 \mathrm{ml}$ and analysed by gas-chromatography (Fison Top 8000) coupled to electron capture detection under the following conditions:

Injection system: on-column (volume injected: $1 \mu \mathrm{l}$ ).

Column: CP-Sil-8 CB, $50 \mathrm{~m} \times 0.25 \mathrm{~mm}$ I.D., film thickness 1.2-2 $\mu \mathrm{m}$.

Temperature program: from 60 to $180{ }^{\circ} \mathrm{C}$ at $20{ }^{\circ} \mathrm{C}$ $\mathrm{min}^{-1}$, followed by a run from 180 to 250 at $3{ }^{\circ} \mathrm{C} \mathrm{min}{ }^{-1}$ and a further run from 250 to 270 at $2{ }^{\circ} \mathrm{C} \mathrm{min}^{-1}$.

Carrier gas: helium at $0.7 \mathrm{ml} \mathrm{min}^{-1}$.

Auxiliary gas: nitrogen at $30 \mathrm{ml} \mathrm{min}^{-1}$.

Quantitative DDT homologue analyses were performed with the external standard method using as reference standard a solution containing pp'DDT, pp'DDE, pp'DDD, op'DDT, op'DDE, op'DDD, prepared from single pure compounds (Alltech) in n-hexane.

The detection limit was $0.05 \mathrm{ng}^{-1}$ for each DDT homologue.

\subsection{Load calculations}

River loads $\left(\mathrm{kg} \mathrm{y}^{-1}\right)$ were calculated according to Sonzogni (Sonzogni et al. 1978) using the following equation:

$$
L=\frac{\sum_{i=1}^{n}\left(C m_{i} Q_{i}\right)}{\sum_{i=1}^{n} Q_{i}} \times Q_{a} \times \frac{1+\frac{1}{n} \times \frac{S_{Q L}}{m_{L} m_{Q}}}{1+\frac{1}{n} \times \frac{S_{Q}^{2}}{m_{Q}^{2}}}
$$

where $\mathrm{Cm}_{\mathrm{i}}$ and $\mathrm{Q}_{\mathrm{i}}$ are the pollutant concentrations and the river discharges, respectively. For the latter, the value of the sampling day was used. $Q_{a}$ is the average annual discharge of each river.

The model accounts for the asymmetrical distribution of the concentration and discharge values with $m_{L}$, $m_{Q}, S_{Q L}, S_{Q}{ }^{2}$ calculated according to the following equations:

$$
\begin{gathered}
m_{Q}=\frac{\sum_{i=1}^{n} Q_{i}}{n} \\
S_{Q L}=\frac{\sum_{i=1}^{n} Q_{i} L_{i}-n \times m_{l} m_{Q}}{n^{-1}}
\end{gathered}
$$

where $n$ is the number of samples collected during one year.

\section{RESULTS AND DISCUSSION}

A drastic change in DDT homologues composition was observed between the two sampling campaigns: op' isomers were always below the detection threshold during 2001-2002, and the parental compound pp'DDT was not detectable $\left(<0.05 \mathrm{ng} \mathrm{l}^{-1}\right)$ in most of the samples
(Tab. 1) while the metabolite pp'DDE was frequently detected, mainly in the dissolved fraction. DDT homologues were always below the WHO and European quality standards for drinking purposes $\left(0.1 \mu \mathrm{g} \mathrm{l}^{-1}, \mathrm{FAO} / \mathrm{WHO}, 2001\right.$; $0.01 \mu \mathrm{g}^{-1}$, Directive 2000/60 EC). The Italian law (D.L. n.152/2006), which came into force in 2006, adopted the same value for pp'DDT in surface water.

DDT homologues concentrations were one or two orders of magnitude lower than those reported in the literature for freshwater in developing countries where DDT is still in use (i.e. Lalah et al. 2003; Zhou et al. 2006) and only sometimes higher than those measured in the freshwater of European countries (i.e. Golfinopoulos et al. 2003; Salvado et al. 2006) where DDT has been banned since the end of sixties.

Pesticide contamination increases in late spring in Northern Italian rivers (Galassi \& Provini 1981; Galassi et al. 1992), even in non-agricultural areas, as a consequence of snow melt at high altitudes (Villa et al. 2006) and rain events favouring polluted soil erosion at lower heights. However, no seasonal trend was clearly recognizable in this study, probably because many of the tributaries of Lago Maggiore (Verzasca, Maggia, Tresa, Bardello) flow from natural or artificial lakes which act as sedimentation traps for hydrophobic pollutants bonded to particulate matter. Lakes in the Lago Maggiore watershed can therefore act either as sinks, in the case of eutrophic environments, or as secondary pollution sources, in the case of artificial reservoirs during maintenance operations involving sediment removal.

The Tresa River, for instance, is the outlet of the eutrophic Lake Lugano: it showed concentration peaks of suspended matter for pp'DDT and pp'DDE in May and for pp'DDE in August, which was very likely associated with the high productivity of phyto and zooplankton in the lake at these times of year.

The Verzasca River, on the other hand, showed maximum pp'DDT and pp'DDE concentrations in December in the dissolved fraction. As this river flows from a reservoir built for hydroelectric power production, the release of pollutants accumulated in the sediment may occur when sediments are removed to prevent infilling.

The annual pesticide loads were calculated for Lago Maggiore tributaries and also for the outflowing Ticino River for the period May 2001-April 2002 (Tab. 2) by the method proposed by Sonzogni (1978), using the discharge values reported in table 3 . This series of data was compared with that of the 1998 study, carried out in similar hydrological conditions (Figs 2 and 3). While pp'DDT loads were shown in the more recent campaign to have greatly decreased (Fig. 2) in comparison to the earlier one in almost all the rivers (Fig. 2), annual loads of pp'DDE were comparable in the two sampling periods (Fig. 3), except for the rivers Maggia and Tresa, which showed a decrease and increase, respectively. 
Tab. 1. pp'DDE and pp'DDT concentrations $\left(\mathrm{ng} \mathrm{l}^{-1}\right)$ in the main inlets of Lago Maggiore and in its outlet (dis. = dissolved; ads. $=$ adsorbed onto suspended solids; n.d. $=$ undetectable; $t \mathrm{r}=$ trace; n.s. $=$ not sampled; interf.= overwhelming peaks).

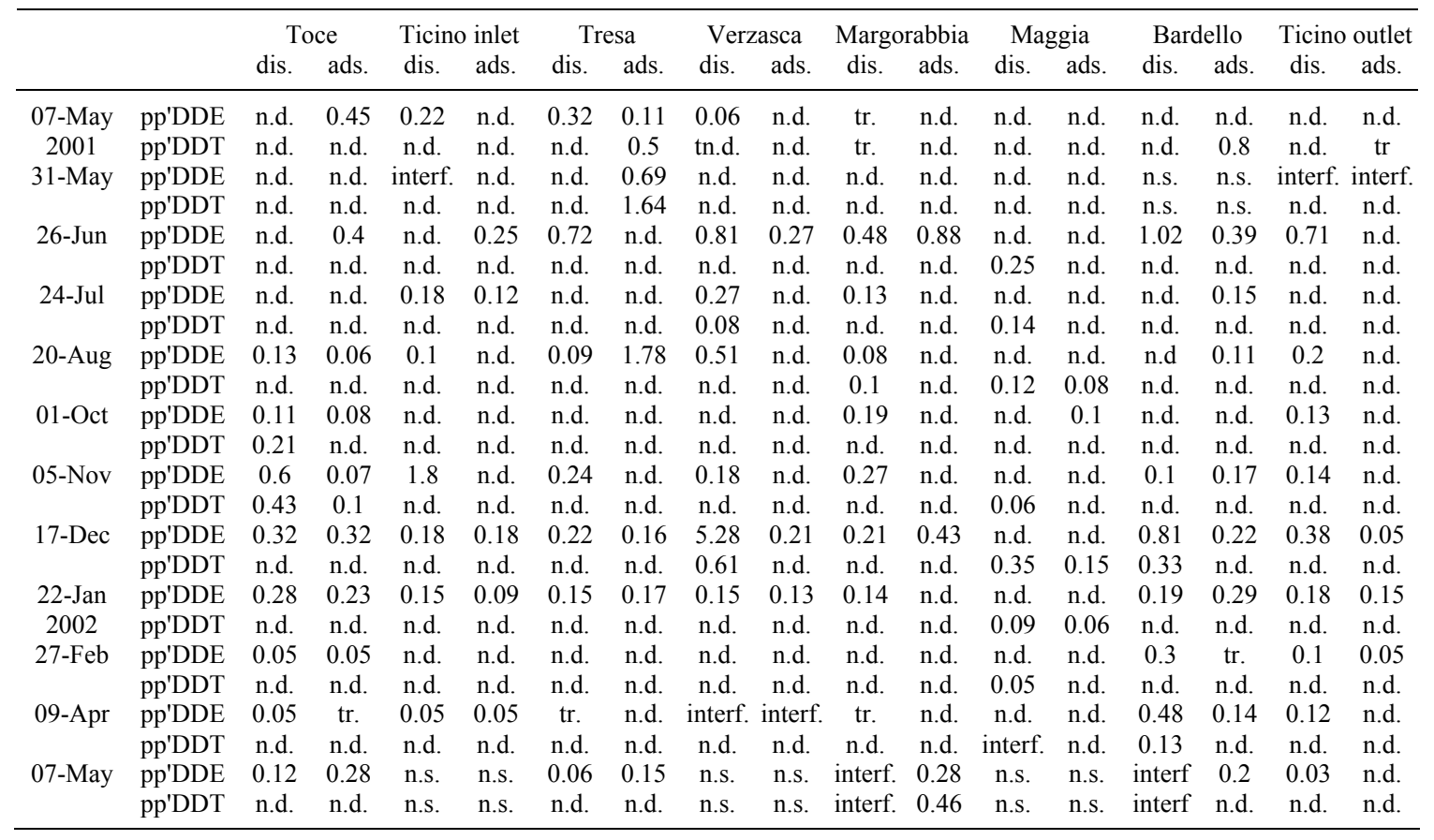

Tab. 2. pp'DDT and pp'DDE loads $(\mathrm{kg})$ in the period in the two sampling campaigns.

\begin{tabular}{lcccc}
\hline & pp'DDT & pp'DDE & pp'DDT & pp'DDE \\
\hline Toce & 0.73 & 0.64 & 0.06 & 0.47 \\
Ticino Inlet & 0.80 & 0.60 & 0.00 & 0.67 \\
Maggia & 0.13 & 0.51 & 0.00 & 0.02 \\
Tresa & 0.11 & 0.16 & 0.17 & 0.37 \\
Bardello & 0.03 & 0.02 & 0.01 & 0.03 \\
Total & 1.8 & 1.93 & 0.24 & 1.56 \\
Ticino Outlet & 1.57 & 1.64 & 0.00 & 1.15 \\
\hline
\end{tabular}

Tab. 3. Daily main dicharge $\left(\mathrm{m}^{3} \mathrm{~s}^{-1}\right)$ of the Lago Maggiore inlets and the outlet Ticino River.

\begin{tabular}{lcccccc}
\hline & Toce & Ticino Inlet & Maggia & Tresa & Bardello & Ticino Outlet \\
\hline May 2001 & 145.97 & 160.30 & 113.57 & 33.05 & 2.40 & 514.50 \\
Jun & 114.44 & 202.37 & 42.8 & 33.93 & 2.70 & 543.44 \\
Jul & 116.18 & 165.72 & 35.70 & 37.33 & 2.86 & 458.84 \\
Aug & 68.20 & 102.14 & 8.85 & 32.59 & 1.78 & 304.06 \\
Oct & 39.23 & 67.79 & 22.90 & 19.79 & 2.87 & 198.25 \\
Nov & 27.43 & 42.67 & 4.88 & 12.64 & 2.46 & 176.08 \\
Dec & 18.26 & 30.44 & 3.78 & 8.17 & 1.86 & 127.54 \\
Jan 2002 & 16.49 & 30.42 & 3.41 & 7.57 & 1.82 & 47.00 \\
Feb & 19.10 & 30.09 & 4.96 & 14.29 & 2.30 & 79.64 \\
Apr & 26.25 & 34.93 & 4.78 & 14.54 & 2.07 & 150.45 \\
May & 183.89 & 161.11 & 113.57 & 103.57 & 7.00 & 170.00 \\
Mean & 62.95 & 86.77 & 10.26 & 28.44 & 2.77 & 251.8 \\
\hline
\end{tabular}




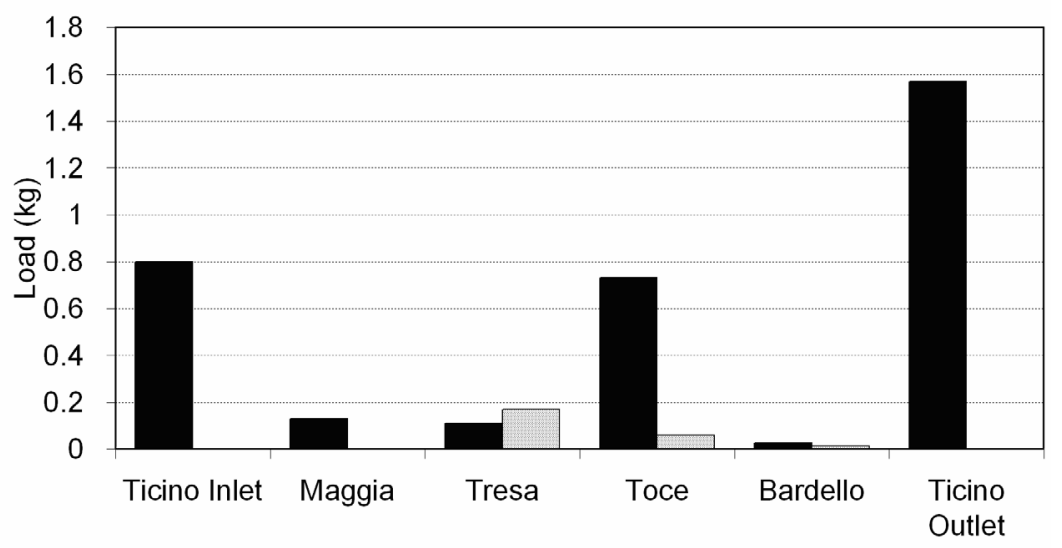

— 1998 pp'DDT

$\square$ '01-'02 pp'DDT

Fig. 2. Loads of pp'DDT in the two sampling campaigns.

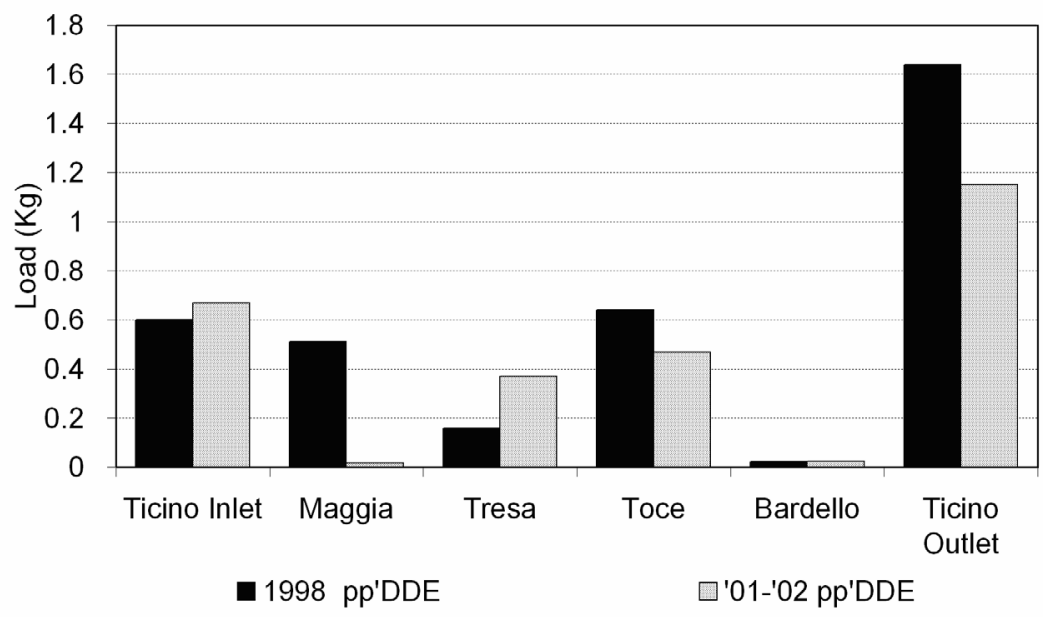

Fig. 3. Loads of pp'DDE in the two sampling campaigns.

The pp'DDT pollution measured in 1998 was probably the result of its release from contaminated soil and sediments in the vicinity of the DDT producing plant. However, it would be reasonable to think that, after four years, most of the parent compound has been metabolized or strongly bound to particles, given that environmental half-life times ranging from 2 to 15 years are reported in the literature for this compound, and solar radiation modifies active soil sites, increasing the strength of DDT binding (Nair et al. 1992).

Moreover, the remediation measures adopted to restore the aquifer under the DDT plant and to contain sediment and soil release in the industrial area should also have contributed to limiting the spread of the pollution from the industrial area.

The situation is different for pp'DDE: in this case the downward trend is less marked, probably because this compound has higher persistence and mobility (Boul 1995) than pp'DDT. On the other hand, little is known about the biodegradation of pp'DDE (Aislabie et al. 1997), which can presumably vary greatly in different environmental conditions.

One way in which pp'DDE can disappear is through photolysis of the particulate fraction (White 1976) in running waters. The half-life of pp'DDE adsorbed to suspended sediments is between 0.9 and 6 days (Zeep et al. 1977). However, sunilight only reaches a very small fraction of the suspended solids in the Toce River, which is muddy in its final reach.

The Ticino and the Toce, the largest rivers in the Lago Maggiore watershed, made the greatest contribution to both DDT and DDE loads in the first campaign. However, the contribution of the River Toce was not much greater than that of the Ticino Inlet, in spite of the fact that the DDT plant site was located within the Toce basin.

It is probable that air transport and cold condensation, which are responsible for trapping DDT and DDE in high mountain glaciers, have a greater influence on the recharge of the Ticino Inlet, which rises in the St. 
Gotthard Massif in Switzerland at $2480 \mathrm{~m}$ a.s.l., than the Toce, which rises at $1720 \mathrm{~m}$ a.s.l. and forms a 147 metre waterfall at the beginning of its course. The situation was similar in the second campaign (20012002), though in this case the load of the parent compound from the Toce was much smaller, with the distribution of pp'DDE at the basin scale apparently even more controlled by climatic conditions.

The pollutant loads of the lake outflow were only slightly lower than the sum of the tributary loads in both sampling campaigns, indicating that only a small portion of the pesticides entering the lake was removed by sedimentation. This is probably caused by the mesooligotrophic condition of the lake (Marchetto et al. 2004) and the consequent low capacity for sequestration of hydrophobic chemicals by phytoplankton (Dachs et al. 2000).

Using the DDT homologue concentrations and loads from the bulk deposition collected monthly at four sampling stations (Pallanza, Locarno, Alpe Robiei and Alpe Devero) in the Lago Maggiore watershed (Guzzella 2002 ) during the same period as the river water analysis (from May 2001 to May 2002), the annual loads were calculated at the basin scale (6599 $\mathrm{km}^{2}$ ) as $3.17 \mathrm{~kg} \mathrm{y}^{-1}$ of pp'DDT and $2.47 \mathrm{~kg} \mathrm{y}^{-1}$ of pp'DDE.

According to this calculation, the tributary load is equal to $63 \%$ of the atmospheric load for pp'DDE but only $7.5 \%$ for pp'DDT. It must be stressed, however, that the rain load includes both dissolved and particulate pollutants, and that particulate pp'DDT is probably the prevailing form in which the compound is transported, both in air and in water.

Although we cannot distinguish the contributions of dry and wet deposition in bulk rain analyses, it can be assumed that most of the pp'DDT was adsorbed on atmospheric particles which were retained by soils and was able to reach running water only through solid transport.

The different behaviour of the two compounds can be explained on the basis of their physico-chemical properties (Tab. 4). The octanol-air partition coefficient $\left(\mathrm{K}_{\mathrm{oa}}\right)$ is usually considered when evaluating the affinity of organochlorine compounds for the atmosphere (Finizio et al. 1997). Recently, MacLeod \& Mackay (2004) identified a threshold of 9 of $\log \mathrm{K}_{\mathrm{oa}}$ above which chemicals are primarily distributed in the gas phase and below which they are primarily bound to atmospheric particles. Interestingly, pp'DDT and pp'DDE are, respectively, just above and below this threshold.

\section{CONCLUSIONS}

The pollution from the land-based sources of pp'DDT, which was responsible for the contamination of Lago Maggiore up to 1998, was much lower during 2001-2002. On the other hand, the metabolite pp'DDE is decreasing slowly, probably because it is being cycled within the watershed.

Elimination of the pollutant through transport outside the Lago Maggiore basin via the outlet river is limited, and degradation processes will take decades. The decline of this stable metabolite was probably also less recognizable because it was produced by the breakdown of the remaining parent pp'DDT.

Furthermore, the recovery of Lago Maggiore from DDT homologue contamination might be delayed by river floods and by the re-suspension of river and coastal sediments. However, these events are unlikely to greatly influence pollutant cycling at the basin scale, since this study has shown a pronounced reduction in pollution in spite of the exceptional floods which occurred in autumn 2000.

These occasional events should not stop the natural decline of pollution through degradation processes, storage in the deepest lake sediments, and transportation outside the Lago Maggiore basin.

The restoration measures proposed for the industrial site should therefore be carefully re-considered in light of the results of the present investigation and of those emerging from the surveys which are still in progress, which will provide more evidence about the health of the whole ecosystem.

\section{ACKNOWLEDGMENTS}

We would like to thank the CIPAIS (Commissione Internazionale per la Protezione delle Acque ItaloSvizzere) group which supported this work and Prof. Oscar Ravera for many valuable suggestions.

\section{REFERENCES}

Aislabie, J.M., N.K. Richards \& H.L. Boul. 1997. Microbial degradation of DDT and its residues-a review. New Zealand Journal of Agricultural Research, 40: 269-282.

Boul, H.L. 1995. DDT residues in the environment- a review with a New Zealand perspective. New Zealand Journal of Agricultural Research, 38: 257-277.

Bettinetti, R., V. Croce, S. Galassi. 2005. Ecological risk assessment from the recent case of DDT pollution in Lake Maggiore (Northern Italy). Wat. Air Soil Poll., 162: 385399.

Carollo, A., F. Contardi, V. Libera \& A. Rolla. 1985. Hydroclimatic cartography of the Lake Maggiore drainage basin. Mem. Ist. ital. Idrobiol., 46: 21-40.

Carderoni, A. \& R. de Bernardi (Eds). 1999. Ricerche sulla distribuzione e gli effetti del DDT nell'ecosistema del Lago Maggiore. Rapporto finale sui risultati delle indagini. CIPAIS: $81 \mathrm{pp}$.

Dachs, J., S.J. Eisenreich, R.M. Hoff. 2000. Influence of eutrophication on air-water exchange, vertical, fluxes, and phytoplankton concentrations of persistent organic pollutants. Environ. Sci. Technol., 34: 1095-1102.

Directive of the European Parliament and of the Council 23 October 2000 n. 60. Framework for Community action in the field of water policy. Official Journal European Communities n. 327, 22/12/2000: 72 pp.

EPA,1999.http://www.epa.gov/reg5oh20/fiels/FIELDSITE/V ELSICO/PAGES/HOMTX.HTM 
FAO/WHO. 2001. Pesticides residues in food -2000 . Evaluations - 2000. Part II - Toxicology. Joint FAO/WHO Meeting on Pesticides Residues. Geneva, World Health Organization.

Finizio, A., D. Mackay, T.F. Bidleman \& T. Harner. 1997. Octanol-air partition coefficient as a predictor of partitioning of semivolatile organic chemicals to aerosols. Atm. Environ., 31: 2289-2296.

Galassi, S. \& A. Provini.1981. Chlorinated pesticides and PCBs contents of the two main triburaries into the Adriatic Sea. Sci. Total Environ., 17: 51-57.

Galassi, S., L. Guzzella, M. Mingazzini, L. Vigano, S. Capri \& S. Sora. 1992. Toxicological and chemical characterization of organic micropollutants in river Po waters (Italy). Wat. Res., 1: 19-27.

Giesy, J.P., A. Lori, A. Feyk, P.D. Jones, K. Kannan \& T. Sanderson. 2003. Review of the effects of endocrinedisrupting chemicals in birds. Pure Appl. Chem., 75 : 2287-2303.

Golfinopoulos, S.K., A.D. Nikolaou, M.N. Kostopoulou, N.K. Xilourgidis, M.C. Vagi \& D.T. Lekkas. 2003. Organochlorine pesticides in the surface waters of Northern Greece. Chemosphere, 50: 507-516.

Guzzella, L., C. Rosicoli, A. De Polis, R. Mosello, A. Barbieri \& A. Pranzo. 2002. Ricerche sulle precipitazioni atmosferiche. In: Calderoni, A. (Ed.). Monitoraggio della presenza del DDT e di altri contaminanti nell'ecosistema del Lago Maggiore, Rapporto Annuale. CIPAIS: 59-68.

Lalah, J.O., P.O. Yugi, I.O. Jumba \& S.O. Wandinga. 2003. Organochlorine Pesticide Residues in Tana and Sabati Rivers in Kenya. Bull. Environ. Contam. Toxicol., 71: 298-307.

MacLeod, M. \& D. Mackay. 2004. Modeling transport and deposition of contaminants to ecosystems of concern: a case study for Laurentian Great Lakes. Environ. Poll., 128: $241-250$.

Marchetto, A., A. Lami, S. Musazzi, J. Massaferro, L. Langone \& P. Guilizzoni. 2004. Lake Maggiore (Italy) trophic history: fossil diatom, plant pigments, and chironomids, and comparison with long-term limnological data. Quaternary International, 113: 97110.

Nair, A., T. Samuel, M.K.K. Pillai. 1992. Behaviour of DDT in three soils exposed to solar radiations under different conditions, Perst. Sci., 43: 333-340.

Received: May 2006

Accepted: August 2006
Ordinanza Ministeriale del 18/07/1990, quantità massime di residui delle sostanze attivedei presidi sanitari tollerate nei prodotti destinati all'alimentazione, Supplemento ordinario n. 57 della Gazzetta Ufficiale - Serie generale del 30/08/1990 n. 202.

Salvado, V., X.D. Quintana \& M. Hidalgo. 2006. Monitoring of nutrients, pesticides and metals in waters sediments and fish in wetland. Arch. Env. Contam. Tox., 51(3): 377386.

Shoeib, M. \& T. Harner. 2002. Using measured octanol-air partition coefficients to explain environmental partitioning of organochlorine pesticides. Environ. Tox. \& Chem., 21: 984-990.

Sonzogni, W.C., T.J. Monteith, W.N. Bach \& V.G. Hughes. 1978. United States Great Lakes Tributary Loadings. International Reference Group on Great Lakes Pollution From Lands Use Activities. International Joint Commission: $187 \mathrm{pp}$.

Vershueren, K., 1983. Handbook of Environmental Data on Organic Chemicals, 2nd Ed. Van Nostrand Reinhold Company, New York, $1310 \mathrm{pp}$.

Villa, S., M. Vighi, V. Maggi, A. Finizio \& E. Bolzacchini. 2003. Historical trends of organochlorine pesticides in an Alpine glacier. J. Atm. Chem., 46: 295-311.

Villa, S., C. Negrelli, A. Finizio, O. Flora \& M. Vighi. 2006. Organochlorine compounds in ice melt water from Italian Alpine rivers. Ecotox. \& Environ. Saf., 63: 84-90.

Wheatley, G.A., 1965. The assessment and persistence of residues of organochlorine insecticides in soils and their uptake in crops. Ann. appl. Biol., 55: 325-329.

White, J.L. 1976. Clay-pesticide interactions. In: Kaufman, D.D., G.G. Still, G.D. Paulson, S.K. Baoudal (Eds). Bound and cojugated pesticide residues. American Chemical Society: 208-218.

Zepp, R.G., N.L. Wolfe, L.V. Azarraga, R.H. Cox, C.W. Pape. 1977. Photochemical transformation of pp'DDT and metoxychlor degradation products, DDE and DMDE, by sunlight. Archiv. Environ. Cont. Tox., 6: 305-314.

Zhou, R. L. Zhu, K. Yang \& Y. Chen. 2006. Distribution of organochlorine pesticides in surface water and sediments from Qiantang River, East China. J. Haz. Mat., A137: 6875. 